\title{
Social support and subjective well-being among elderly Chinese empty-nester: Self-worth as a Mediator and self-reported health as a Moderator
}

Hong Su ( $1028106795 @ q q . c o m$ )

Harbin Medical University https://orcid.org/0000-0001-6312-763X

\section{Yuqiu Zhou}

Harbin Medical University

Jianqin Cao

Harbin Medical University

Haina Wang

Harbin Medical University

\section{Research}

Keywords: Self-worth, Self-acceptance, subjective well-being, empty-nest elderly

Posted Date: January 10th, 2020

DOI: https://doi.org/10.21203/rs.2.20625/v1

License: (c) (i) This work is licensed under a Creative Commons Attribution 4.0 International License. Read Full License 


\section{Abstract}

\section{Purpose}

This study aimed to explore the relationship between social support, self-worth, self-reported health, and subjective well-being among the Chinese rural empty nest elderly, and whether self-worth and selfreported health affect these associations.

\section{Methods}

This cross-sectional study was performed from May 2017 to April 2018, the participants were 365 emptynest elderly adults from rural areas of Chifeng City in Inner Mongolia. Data were collected with the General information questionnaire, Self-worth questionnaire for adults, Social Support Scale and Memorial University of New Found land Scale of Happiness. Structural equation modeling was used to test the mediation hypothesis. Bootstrapping was performed to confirm the mediation effect. Hayes's SPSS-PROCESS was used for testing the moderating effects.

\section{Results}

Self-worth showed significant correlations with social support, self-reported health and subjective wellbeing (all $\mathrm{P}<0.01$ ).Bootstrapping indicated that the mediating role of self-worth was statistically significant. And self-reported health moderated the social support and subjective well-being association.

\section{Conclusions}

Self-worth and self-reported health are important targets for prevention and intervention for improving the subjective well-being of the rural empty-nest elderly.

\section{Introduction}

Population aging is a worldwide social phenomenon. Currently, China represents the largest elderly population in the world. In China, the number of empty-nest elderly families with only an old couple or one aged person is increasing, which is closely related to China's overall economic environment, such as the accelerated process of urbanization, the imbalance of economic development between the inland and coastal regions, and the flow of rural surplus labor to large and eastern coastal cities ${ }^{[1]}$. In 2014, one survey conducted by China National Committee on Ageing announced that empty-nesters accounted for $51.1 \%$ of the elderly in China ${ }^{[2]}$. The number of empty nest families is expected to reach $90 \%$ in $2030^{[3]}$.Due to the lack of emotional comfort, health care, life care, etc, the empty-nest elderly were widespread "empty nest syndrome". Furthermore, loneliness is associated with a higher risk of clinical depression ${ }^{[4]}$,Alzheimer's disease ${ }^{[5]}$ suicidal ideation and hypertension ${ }^{[6]}$. Loneliness also is a risk factor for increased morbidity and mortality ${ }^{[7]}$ in older people. However elderly people's mental health is often 
overlooked. Mental health disorders in the empty-nest elderly may decrease their social and physical activities, generate unsociability and self-grief and reduce their quality of life.

Subjective well-being (SWB) is the overall life satisfaction and happiness, it is an important comprehensive psychological index to measure individual life quality. SWB provides a meaningful and complementary measure of health of older adults, when compared to objective measures, as SWB involves older adults' subjective appraisals of their life in older age from their own perspective Empty nest elderly were in a negative emotional situation for long time, it will be bad for their mental health and subjective well-being. Loneliness may lead to lower subjective well-being ${ }^{[8]}$.

In recent years, studies on the relationship between social function and SWB of the elderly have become popular ${ }^{[9]}$. Social support is an important predictor of life satisfaction throughout an individual's life ${ }^{[10]}$. The main effect model suggests that the enhanced social support in any case can generally increase the level of one's mental health, whereas the stress buffering model states that social support can mitigate the influence of stress events on an individual's mental health when people face stress events. These theoretical models indicate that social support can help individuals produce favorable psychological outcomes and thus enhance one's SWB ${ }^{[11]}$. Mason's research discovered that social support was positively related to psychological well-being ${ }^{[12]}$. Self worth has been identified as the individual loving and accepting themselves, and the lasting self-worth is a relatively stable personality characteristic ${ }^{[13]}$, it is associated with subjective well-being. Mark Leary's research ${ }^{[14]}$ showed that self-worth can adjust interpersonal relationship, make it more harmony, and there were reason-result relationships between self worth and interpersonal relationships attribution each other. These findings highlight that good social support is a protective factor for elderly SWB. However, its mediating and moderating mechanisms remain largely unknown. A clearer understanding of the mechanisms is important to develop an effective intervention for improving the elderly Chinese rural empty-nester's subjective well-being. In this study, we aim to examine two questions: (1) whether social support increases self worth, which in turn increases the likelihood of subjective well-being; (2) whether this indirect association is moderated by self-reported health.

\section{Self-worth as a Mediator}

Self-worth is a person who cognize and evaluate themselves in a social activities (including group and others) ${ }^{[15]}$. According to the stress-and-coping model ${ }^{[16]}$, when individuals appraise a negative event (e.g., discrimination) as stressful, they perceive their self-image to be threatened. This threat may have significant prediction for an individual's self-evaluation, which may, in turn, directly link with their levels of psychological well-being. Self-worth and subjective well-being are involved in the evaluation of emotional experience and emphasize individual self-awareness ${ }^{[17]}$. Chen's study indicated that self-worth level is one of important factors that produce effects on elderly' s mental health, and it is related to subjective well-being and life satisfaction level ${ }^{[18]}$. When people are getting older, their self-worth level will decrease continuously the positive self-worth will promote the individual mental health. The social support is one 
of important factors that produce effects on empty nesters' mental health ${ }^{[1]}$ (Liu \& Guo,2007). The elderly with low level social support will obtain less objective support and subjective support, when they encounter difficulties in life they will feel so inadequate, anxiety and fear are eventually followed by varied degrees of depression and sadness, lead to a decline in self-worth. The relationship between social support, self -worth and subjective well-being among college students has been revealed in previous studies ${ }^{[19]}$. However, few studies have focused on self-worth as the mediator between social support and s subjective well-being among empty-nest elderly. Based on these arguments, we propose the following hypothesis:

Hypothesis 1

Self-worth will mediate the relationship between social support and subjective well-being.

\section{Self-reported health as a moderator}

Although social support and self-worth are the important factors affect subjective well-being. The relationship between social support and subjective well-being will change due to other factors. Selfreported health is thought to both summarize the effects of functional impairment and physical disease, which could evaluate and predicate the health status in elders ${ }^{[20]}$.Cho's research ${ }^{[21]}$ showed that health damage have significant direct effects on subjective well-being among older people(Cho et al.2011). Objective medical diagnoses of physical illness and functioning have long been used in an attempt to understand the relationships between psychological distress and health in the elderly ${ }^{[22]}$. However, recent research has found that the more subjective measure of health-self-reported health-appears to have a stronger association with psychological distress than physician-reported health and is possibly more important as a predictor of overall physical well-being than the more objective measures ${ }^{[20]}$. According to Meng's investigation the self-reported health of elderly is associated with social support, the higher level of social support, the better self-reported health the elderly has ${ }^{[23]}$, which in turn increases the level of subjective well-being. However, whether self-reported health can moderate the association between selfworth and subjective well-being in rural empty-nest elderly remains uncovered. Based on the above theoretical analyses and evidence, we propose the following hypothesis:

Hypothesis 2

Self-reported health will moderate the he relationship between social support and subjective well-being

\section{Methods}

\section{Location}

Chifeng City is in the eastern parts of Inner Mongolia in China with a population 24.8171 million, people aged over 60 was 4.373 million, accounting for $17.6 \%$ of its population. As an ethnic minority region, Inner Mongolia autonomous region has its special production (industry, agriculture and animal 
husbandry), life style and cultural background. Due to poor soil, and water supply, the low yield of agricultural and sideline products, agricultural earnings very little. Given this, many young people go to work in the cities some farmers have established their careers in those cities and become urban dwellers, while their parents are left behind in rural homes.

\section{Participants}

This study was a cross-sectional study carried out by researchers from Harbin Medical University from May 2017 to April 2018 in Chifeng City in the eastern parts of Inner Mongolia in China. A multistage stratified random sampling method was used. Step 1:We selected one region randomly from three regions of Chifeng City, and then six streets were selected from this region randomly. Finally, we selected three communities from each street randomly with a total of 18 residential committees extracted. Step 2: Using simple random sampling in accordance with the information provided by community workers, empty-nest elderly were selected randomly from the 18 residential committees. All the respondents completed a household questionnaire survey and provided informed consent after receiving information about the goals and the methods of the investigation. The ethics committee of the university approved the study, which was completed in accordance with the Declaration of Helsinki.

A total of 365 empty-nester elderly adults in Chifeng Country were invited to participate in the study. The sample only included adults aged 60 and above who lived in Chifeng. The inclusion criteria were: (1) age $\geq 60$, (2) living at the survey site for at least 6 months, (3) being at home during the investigation period, and (4) able to participate in the study. Exclusion criteria were as follows: childless elderly, dementia, Parkinson disease, schizophrenia, seizures, claustrophobia, bipolar disorder, brain tumor, secondary hypertension, end-stage heart disease, renal failure and dialysis treatment, connective tissue diseases, malignancy, contraindication to MRI, and unwillingness or difficulty in providing informed consent. 639 elderly living in the selected areas, 428 met the inclusion criteria, 365 of whom returned questionnaires for a response rate of $85.28 \%$. (as shown in Fig. 1).

\section{Measures}

\section{The general information questionnaire}

The general information questionnaire was used to assess the demographic information, including age, gender, family income, degree of education, marital status, self-reported health status and other information. The degree of education was divided into primary school and below, secondary school, high school, and college graduate or above. Marital status was divided into single (never married), married, divorced/separated. Household monthly income was categorized as "low, $\leq 1000 \mathrm{rmb}$ ( $\approx 158$ dollars)", "middle, 1001 2000rmb" or "high, > 2000rmb". Self-reported health is the elderly to evaluate their own health, five response categories ranging from "very poor"(1 point)to "very good"(5points) . 


\section{The Adult Self-worth Questionnaire}

The Adult Self-worth Questionnaire, used to assess self-worth, was developed by Yanping Luo ${ }^{[24]}$,selfworth was measured using six dimensions, which included family relations, personal qualities, communication, physical appearance, life attitude and social relations. The questionnaire consists of 28 items. Each item has five response categories ranging from "do not fit" (1 point) to "very fit" (5 points), the total score range from 28 to 140, and higher scores indicated better self-worth. The questionnaire has been used in Chinese older men and demonstrated good reliability and validity, with Cronbach's alphas for the total scale 0.899 .

\section{Social Support Scale(SSRS)}

The Social Support Scale was used to measure the social support of the rural empty-nester elderly, which was developed by Shuiyuan Xiao ${ }^{[25]}$. This questionnaire contains 10 items belonging to 3 factors: subjective support, objective support, and utilization degree. The total score ranges from 12 to 60 , and higher scores indicate better social support. The Cronbach's alpha coefficient of the scale was $0.814^{[26]}$.

\section{Memorial University of New Found land Scale of Happiness, (MUNSH)}

The Memorial University of Newfoundland Scale of Happiness ${ }^{[27]}$ (MUNSH) was used to assess respondents' subjective level of well-being over the prior couple of months. This is a 24-item, selfcompletion scale with 'yes' or 'no' responses that includes five items measuring positive attitudes (PA), five items measuring negative attitudes (NA), seven items measuring positive experiences (PE), and seven items measuring negative experiences (NE). Each 'positive' response is scored as ' 1 ' and each negative response is scored as ' -1 ', but when computing the subscale scores and total scale score these are converted to a positive range so the range of values for the PA and NA subscales scores are $0-10$, the range for the $\mathrm{PE}$ and $\mathrm{NE}$ subscales scores are $0-14$, and the range for the total scale score is $0-48$. For the Chinese version of the MUNSH, the test-retest reliability of the total score (using Spearman's correlation coefficient) is 0.87 and the internal validity of the 25 items in the full scale (using alpha) is $0.76^{[28]}$.

\section{Data Analysis}

Mean values were reported with standard deviations (SD), Pearson's correlations for continuous variables to investigate the relationship between social support, self-worth; self-reported health and subjective wellbeing. Harman single factor test was used to investigate common method biases Data were analyzed using SPSS 22. The alpha value was set at 0.05 .

We used AMOS 17.0 to perform structural equation modeling with the full-information maximum likelihood estimation method to examine mediation effects. Baron and Kenny's analysis technique [29] was used for testing the hypothesis concerning the mediation effect of self-worth on the relationship between the social support and subjective well-being. 
The model 59 of Hayes's SPSS-PROCESS was used for testing the moderating effects of self-reported health on social support, self-worth and subjective well-being. For each model, $\mathrm{Cl}$ for the conditional indirect effects (i.e., at +1 SD or -1 SD of the moderator) were generated with simple effect analysis.

\section{Results}

\section{Descriptive Analyses}

From May 2016 to April 2018,365 elderly people aged 60 years or over were screened from nine villages in the area of Chifeng city in Inner Mongolia, China. Empty-nest elderly were defined as those who have children but do not live with their children. 98 cases were full empty-nest elderly (those do not live with their children in the same city or have no children), 267 were partial empty-nest elderly (those who live with their children in the same city but do not live together), and 78 were solitary $\mathbb{2} 287$ were couples who live together. The age of these respondents ranged from 60 to 86 years (mean $=70.87 \pm 6.21$ years). $144(39.45 \%)$ were male, and $221(60.55 \%)$ were female. The level of education was predominantly primary and middle school. (205 cases, $56.16 \%$ ) with an average number of years of education of $8.4 \pm$ 2.3 years. Monthly income was mostly $₫ 1000$ yuan $(72.57 \%)$.

\section{Preliminary Analyses}

Table 1 displays the means and standard deviations of the variables representing social support,selfworth, self-reported health and subjective well-being, and correlations for all variables in the current study. In our study, correlational analyses indicated that self-worth was significantly positively correlated with social support, self-reported health and subjective well-being.

Table 1

Means, standard deviations, and correlations of the main study variables

\begin{tabular}{|lllll|}
\hline Variables & $\mathbf{1}$ & $\mathbf{2}$ & $\mathbf{3}$ & $\mathbf{4}$ \\
\hline (1)social support & 1 & - & - & - \\
\hline (2)self-worth & $0.763^{* \star}$ & 1 & - & - \\
\hline (3)subjective well-being & $0.539^{\star \star}$ & $0.599^{\star \star}$ & 1 & - \\
\hline (4)self-reported health & $0.572^{* \star}$ & $0.626^{* \star}$ & $0.735^{* \star}$ & 1 \\
\hline M & 33.18 & 103.12 & 35.98 & 2.43 \\
\hline SD & 5.41 & 11.55 & 2.40 & 0.97 \\
\hline Note: ${ }^{* *} \mathrm{p}<0.01$. & & & & \\
\hline
\end{tabular}




\section{The mediation of self-worth in the relationship between social support and subjective well-being}

Several indices were calculated to evaluate the model fit to the data: chi-square statistic $\left(\chi^{2}\right), \chi^{2} / d f$, root mean square error of approximation (RMSEA), goodness-of-fit index (GFI), adjusted goodness of-fit index (AGFI), and normed fit index (NFI). Throughout the study, a model was considered to have a good fit if all the path coefficients were significant at the 0.05 level, $\chi^{2} / d f<3$, the RMSEA was below 0.05 , and the NFI and GFI were greater than 0.9 .

In this study, the structural equation model of self-worth and self-acceptance affecting subjective wellbeing had $\chi^{2} / \mathrm{df}=1.387 ; \mathrm{RMSEA}=0.033 ; \mathrm{GFI}=0.995 ; \mathrm{AGFI}=0.959 ; \mathrm{NFI}=0.982$. The model fit was quite good. All the loadings of the indicators were significant at the 0.01 level, indicating good convergent validity. Social support had a direct effect on subjective well-being $(\beta=0.31, P \unrhd 0.05)$. Figure 2 shows that social support had a direct effect on self-worth $(\beta=0.90, P \otimes 0.01)$. Self-worth had a direct effect on self worth $(\beta=0.33, P \llbracket 0.05)$. Moreover, bootstrapping analyses indicated that self worth partially mediated the relation between social support and subjective well-being [indirect effect $=0.474, \mathrm{SE}=0.323,95 \% \mathrm{Cl}$ $(0.162,0.344)]$.

\section{Self-reported health as a moderator between social support and subjective well-being}

Control the variables of gender, age, level of education and occupation, the social support total score was the independent variable, self-worth was the mediators, self-reported health was the moderators and subjective well-being was the dependent variable. And the these data are standardized, the data were analyzed with the analysis of Hayes's SPSS-PROCESS, multivariate linear stepwise regression showed that self-reported health moderated the association between social support and subjective well-being, and between self-worth and subjective well-being ( $\beta=-0.152, P \otimes 0.001 ; \beta=0.828, P \otimes 0.001)$. However, there was no significant interaction between social support and self-reported health to predict self-worth ( $\beta$ $=-0.542, P=0.185$ ) (Table 2). 
Table 2

Multivariate hierarchical regression analysis

\begin{tabular}{|c|c|c|c|c|c|c|c|c|}
\hline \multirow[t]{2}{*}{$\begin{array}{l}\text { Independent } \\
\text { variables }\end{array}$} & \multicolumn{4}{|c|}{$\begin{array}{l}\text { Dependent } \\
\text { variable: Self- } \\
\text { worth }\end{array}$} & & \multicolumn{2}{|c|}{$\begin{array}{l}\text { Dependent } \\
\text { variable: } \\
\text { Subjective well- } \\
\text { being }\end{array}$} & \multirow[b]{2}{*}{$\mathbf{P}$} \\
\hline & $\beta /$ Coef & SE & $t$ & $\mathbf{P}$ & $\beta /$ Coef & SE & $\mathrm{t}$ & \\
\hline Social support & 1.823 & 0.120 & 15.265 & 0.000 & & & & \\
\hline $\begin{array}{l}\text { Self-reported } \\
\text { health }\end{array}$ & 2.886 & 1.497 & 1.928 & 0.055 & & & & \\
\hline $\begin{array}{l}\text { Social support x } \\
\text { Self-reported } \\
\text { health }\end{array}$ & -0.542 & 0.041 & -1.328 & 0.185 & & & & \\
\hline Self-worth & & & & & -0.167 & 0.037 & -4.458 & 0.000 \\
\hline Social support & & & & & 0.422 & 0.076 & 5.557 & 0.000 \\
\hline $\begin{array}{l}\text { Self-worth } \times \text { Self- } \\
\text { reported health }\end{array}$ & & & & & 0.828 & 0.015 & 5.589 & 0.000 \\
\hline $\begin{array}{l}\text { Social support x } \\
\text { Self-reported } \\
\text { health }\end{array}$ & & & & & -0.152 & 0.028 & -5.328 & 0.000 \\
\hline
\end{tabular}

We conducted simple slope ${ }^{[30]}$ plots and calculations at + 1 SD and - SD from the mean of self worth and as depicted in Fig. 3 and Fig. 4. The positive association between self-worth and Subjective well-being was much stronger for rural empty-nest elderly with higher self-reported health $(b=0.115, S E=0.022, t=$ $5.26, p<0.01)$ compared to empty-nest elderly with lower self-reported health $(b=0.046, S E=0.019, t=$ $2.354, p<0.05)$ (Fig. 3). The relationship between social support and subjective well-being was much stronger for rural empty-nest elderly with lower self-reported health $(b=0.201, S E=0.042, t=4.812, p<$ $0.01)$ compared to empty-nest elderly with higher self-reported health $(b=0.095, S E=0.042, t=2.269, p<$ 0.05) (Fig. 4).

\section{Discussion}

In the present study, we examined the relationships between social support, self-worth, self-reported health, and subjective well-being among the Chinese empty nest elderly. Path analysis modeling indicated that social support affects subjective well-being directly and also affects subjective well-being indirectly via self-worth. The connection between social support and subjective well-being was moderated by selfreported health, and self-reported health also moderate the relationship between self-worth and subjective well-being. Our findings suggest that 
interventions to improve social support have the potential to improve subjective well-being in empty nest elderly. In addition, improvements in social support that may help improve self-worth may also, in turn, increase subjective well-being. Moreover, the self-reported health may help empty nest elderly endure the social support, self-worth associated with their subjective well-being.

\section{The Mediating Role of self-worth}

This study showed that social support played significantly roles in the subjective well-being of rural empty-nest elderly, individuals who score higher on social support were more prone to feelings of happiness and satisfaction. Social support is defined as the provision of physical, emotional, informational, and instrumental assistance that an individual perceives from their social networks ${ }^{[31]}$. Research has shown that older adults with higher levels of social support experience higher perceived health and lower levels of depressive or loneliness symptoms ${ }^{[32,33]}$. This indicates that social support should be recognized as one of the most essential protective factors affecting both mental and physical health among older adults, especially empty nesters ${ }^{[34]}$.

In line with our hypotheses, our results suggest that self-worth mediates the relationships between social support and subjective well-being among rural empty-nest elderly, higher self-worth people usually experience more positive emotions and less negative emotion, lower self-worth was opposite, which is consistent with previous studies ${ }^{[35]}$. Self-worth is a positive predictor of SWB, which is consistent with a

previous study ${ }^{[36]}$. Self-worth is the elderly to judge their own value, empty nest elderly is a special group, they not only experience the restructuration of lifecycle, but also undergo the transformation of familycycle, meanwhile, the organizational structure of individual and brain function changes with aging, the functional activities of the systems significantly decreased, which lead to many psychological problems and barriers. Depression and inferiority are the most frequent emotional issues, these cause they can't accept themselves well, and can't achieve ideal physical and mental health. Self-worth is on behalf of self-esteem and self-acceptance, it is not affected by external condition or the success or failure of the life events. When individual can confront these disadvantages unconditionally, they can change the negative side and constantly improve themselves ${ }^{[37]}$. Therefore, it is very important for empty-nester elderly to promote their self-worth, in order to improve the level of subjective well-being. However, the existing pension policy in China is difficult to meet the needs of the elderly to improve their self-worth. Therefore, community workers should build up the elderly long-term care system, enhancing the training of caregiving personnel, establishing a diversified elderly, it is also important to enhance the economic income as well as self-worth level.

\section{The Moderating Role of Self-reported health}

In line with our hypotheses 2, our results suggest that self-reported moderate the relationship between social support, self-worth and subjective well-being. Self-reported health has been used by many 
researchers as a proxy for measuring individual health state, including that of the elderly ${ }^{[38,39]}$.In regard to functional decline, many factors and comorbid conditions including depression were proven to be related with functional decline in previous studies ${ }^{[40]}$.

In our study low social support, self-worth are associated with worse SWB, self-reported health also could offset the linkage between social support, self-worth and SWB as a moderator. Social support could maintain the good status of self-reported health of the elderly ${ }^{[41]}$, the communities organize various activities to promote the communication and exchanges between the elderly, and improve the social interaction of older adults, which will have a positive impact on the self-reported health. Shield's study indicated that subjective well-being was closely related to health, while the poor health status was negatively associated with personal subjective well-being ${ }^{[42]}$. Previous studies have indicated that elderly people who are good health in less physical dependence on others and had better self-worth, devote the most time and energy to the conversations you enjoy most, and make its subjective feeling more positive ${ }^{[43]}$. Therefore, self-reported health play a positive role In promoting subjective well-being of empty-nesters elderly. Community Health Service Centers should be developed to provide physical and psychological evaluation and treatment.

The results of this study contribute to examine how well a process model that links social support to SWB through self-worth and self-reported health. However several limitations of this study should be noted. First in order to alleviate the effect of social support on SWB from a wider perspective, more additional mediators should be examined by further studies. Second, some data collected under the guidance of the research, because some elderly cannot read or watch, so, the result may have some bias. Third, the present study was a cross-sectional design, which cannot ascertain the directionality of the observed associations. Because of the aforementioned limitations, the analysis of the results in the study should be reviewed cautiously.

\section{Conclusion}

Despite these limitations, this was the first time when the moderated mediation model between social support and SWB was investigated, and the mediation and moderation model were significant. These results could help us better understand the interactive mechanisms of social support and SWB among the Chinese rural empty nest elderly. With the urbanization of our country, and the flow of rural surplus labor to big cities, the population growth in the rural empty nest elderly has shown a rapid trend . The physical and mental health of the rural empty nest elderly, as a vulnerable group in our society, has become an important social problem. In order to aid in the improvement of quality of life among the empty nesters elderly, aged care professional practitioners and our policy makers should not only focus on the social support, but also strengthen the awareness of the role of self-worth and self-reported health.

\section{Abbreviations}


SWB:Subjective well-being; PA:positive attitudes; NA:negative attitudes; PE:positive experiences;NE:negative experiences; $\mathrm{SD}$ :standard deviations

\section{Declarations}

\section{Ethics approval and consent to participate}

The study followed the Declaration of Helsinki on ethics. Ethics approval was obtained from the Harbin Medical University.

\section{Consent for publication}

Written informed consent was obtained from all individual participants included in the study.

\section{Availability of data and materials}

The datasets used in the current study are available from the corresponding author on reasonable request.

\section{Competing interests}

All authors declare they have no conflict of interest.

\section{Funding}

This research was supported by" The Fundamental Research Funds for the Provincial Universities,

Wu Liande Youth Scientific Research Fund of Harbin Medical University-Daqing",funds number"2018wld01 " and College of nursing cultivation fund, fund number"HLPY1803".,

\section{Author's contribution}

Author Contributions Conceived and designed the study: Hong Su. Performed the study: Hong Su and Yuqiu Zhou. Data analysis: Jianqin Cao and Haina Wang. Wrote the paper: Hong Su and Yuqiu Zhou. All authors read and approved the final manuscript.

\section{Acknowledgements}

The authors would like to thank Jiaying Cao for her help in the questionnaire survey.

\section{References}

1.Liu LJ \& Guo Q.Loneliness and health-related quality of life for the empty nest elderly in the rural area of a mountainous county in China. Quality of Life Research, 2007,8, 1275-1280.

2.Chen F, Xu, X.L.; Yang, Z.; Tan, H.W.; Zhang, L. (2015).The willingness-to-pay for general practitioners in contractual service and influencing factors among empty nesters in Chongqing, China. Int. J. Environ. 
Res.2015,12, 9330-9341

3.Li D.M., Chen T Y \&,Lib G Y. The problem of mental health in the elderly In empty-nest family. Chinese Journal of Gerontology,2003,7, 405-407.

4.Chou KL.Moderating effect of apolipoprotein genotype on loneliness leading to depressive symptoms in Chinese older adults. Am J Geriatr Psychiatry , 2010,18: 313-322.

5.Wilson RS, Krueger KR, Arnold SE. Loneliness and risk of Alzheimer disease. Arch Gen Psychiatry , 2007,64:234-240.

6.Hawkley LC, Thisted RA, Masi CM, Cacioppo JT. Loneliness predicts increased blood pressure: 5 year crosslagged analyses in middle-aged and older adults. Psychol Aging,2010,25: 132-141.

7.Perissinotto CM, Stijacic Cenzer I, Covinsky KE. Loneliness in older persons: a predictor of functional decline and death.Arch Intern Med,2012,172:1078-1083.

8.Tian Q. Intergeneration social support affects the subjective well-being of the elderly: Mediator roles of self-esteem and loneliness. J Health Psychol.2016,21(6):1137-1144.

9.Pinquart M and Sörensen S. Influences of socioeconomic status, social network, and competence on subjective well-being in later life: A meta-analysis. Psychology and Aging, 2010,15(2): 187-224.

10.Siedlecki KL, Salthouse TA, Oishi S, et al. The relationship between social support and subjective wellbeing across age. Social Indicators Research,2014, 117(2): 561-576.

11.Cohen S .Psychosocial models of the role of social support in the etiology of physical disease. Health Psychology,1988, 7(3): 269.

12.Mason HO.Multiple measures of family and social support as predictors of psychological well-being: An additive approach. Journal of Educational and Developmental Psychology,2016, 6(2): 97-112.

13.Huang XT. (2006).Time and personality psychology. Beijing[M]. Beijing normal university 2006: 208214.

14.Mark, Leary. Self-esteem as a interpersonal monitor: The sociometer hypothesis. Journal of Personality and Scocial Psychology, 1995,68(3):518-530

15.Huang XT \&Yang X. The development of adolescent students self-worth scale. Psychological science,1998, 4: 289-292.

16.Lazarus, R. S., and Foulkman, S. (1984). Stress, Appraisal, and Coping. New York, NY: Springer.

17.Diener,E \& Diener M. Cross-cultural correlates of life satisfaction and self-esteem. Journal of Personality and Social Psychology,1995, 68,653-663. 
18.Chen JW, Wang T. Review of foreign research on the overall self-esteem. Journal of Ningbo university, 2006,28(2): 17-22.

19.Wu DW. College students' social support, self-worth the study of the influence of subjective well-being [D].2004. Hebei normal university.

20.Kosloski, K., Stull, D. E., Kercher, K., \& van Dussen, D.J. Longitudinal analysis of the reciprocal effects of self-assessed global health and depressive symptoms. Journal of Gerontology, 2005,60B, 296-303.

21.Cho J, Martin P, Martin P, Margrett J, Macdonald M, Leonard W. The Relationship between Physical Health and Psychological Well-Being among Oldest-Old Adults. Journal of Aging Research,2011, 6,1-7.

22.Pinto JM, Fontaine AM, Neri AL. The influence of physical and mental health on life satisfaction is mediated by self-rated health: a study with Brazilian elderly. Arch Gerontol Geriatr,2016,65:104-110

23.Meng QQ, Zhang TH. The old social support and self-care of self-evaluation of health status and life. Medical research journal, 2010,39(11) : 86-89.

24.Luo YP. Preliminary establishment of adult self-worth questionnaire[D]. 2010.Hunan normal university. 25.Xiao SY. Social support scale. Chinese Mental Health Journal, (Supp),1999:127-131.

26. Hu J, Liu XJ, Dai XY, Kou XJ.Wuhan city community empty nesters social support, coping styles, the relationship between self-efficacy and depression, Chinese journal of gerontology ,2018,8(06):1508-1511.

27.Wang XD, Wang XL\& Ma H. Mental Health Rating Scale Manual. Beijing: Chinese Mental Health Journal Press, 1999:186-88.

28.Liu RG\& Gong YX. The application of Memorial University of Newfoundland Scale of Happiness, MUNSH. Chinese Journal of Clinical Psychology , 1999,2,107-108.

29. Cohen J, Cohen P, West SG, West G \& Aiken LS. Applied multiple regression/ correlation analysis for the behavioral sciences. 2003, Thirded. Hills dale. Lawrence Erlbaum Associates.

30.Aiken LS, West SG囚Reno RR.Multiple regression: testing and interpreting interactions [M]. 1991,London: Sage.

31.Lu, M., Yang, G., Skora, E., Wang, G., Cai, Y., Sun, Q, et al. Self-esteem, social support, and life satisfaction in Chinese parents of children with autism spectrum disorder. Research in Autism Spectrum Disorders, 2015,17, 70-77.

32.Wu ZQ, Sun L, Sun YH. Correlation between loneliness and social relationship among empty nest elderly in Anhui rural area China. Aging Ment Health,2010,14(1):108-12. 
33.Su D, Wu XN, Zhang YX et al. Depression and social support between China' rural and urban emptynest elderly. Arch Gerontol Geriatr ,2012,55(3):564-9.

34.Tyler KA. The impact of support received and support provision on changes in perceived social support among older adults. Int J Aging Hum Dev,2006,62(1):21-38.

35.Zhang W,\& Zheng RC. College students' subjective well-being and its influencing factors. Chinese journal of mental health, 2004,1,61-63.

36.John M.Chamberlain DA \& Haaga. Unconditional self-acceptance and psychological health.Journal of Rational-Emotive and Cognitive-Behavior Therapy,2001,19:163-176.

37.Li WG. The present situation and characteristics of research students' self-acceptance. Journal of Ningxia university,2002,1,112-114.

38.Ichoku HE, Fonta W, Thiede M. Socioeconomic gradients in self-rated health: a developing country case study of Enugu state, Nigeria. Econ Change Restructuring. 2011,44(3):179-202.

39.Onadja Y, Bignami S, Rossier C, Zunzunegui MV. The components of self-rated health among adults in Ouagadougou, Burkina Faso. Popul Health Metr,2013,11(1):1.

40.Jackson D L.\& Gillaspy JA. Purc-Stepnson R. Reporting practice in confirmatory factor Analysis: An overview and some recommendations. Psychological Methods,2009, 1,6-23.

41.Wang XH, Huang WY, Yang JY. Guizhou rural poor situation and influencing factors of the elderly health self-assessment analysis, Modern preventive medicine,2013, 40 ( 13) : 2482-5.

42.Shields M A『Wheatley PS. Exploring the economic and social determinants of psychology well-being and perceived social support in England. Journal of royal statistics society, 2005,168(3) : 513-537》

43.Wang WP. The community elderly self-worth status and its influencing factors is analyzed [D]. 2017 ,North China university of technology.

\section{Figures}




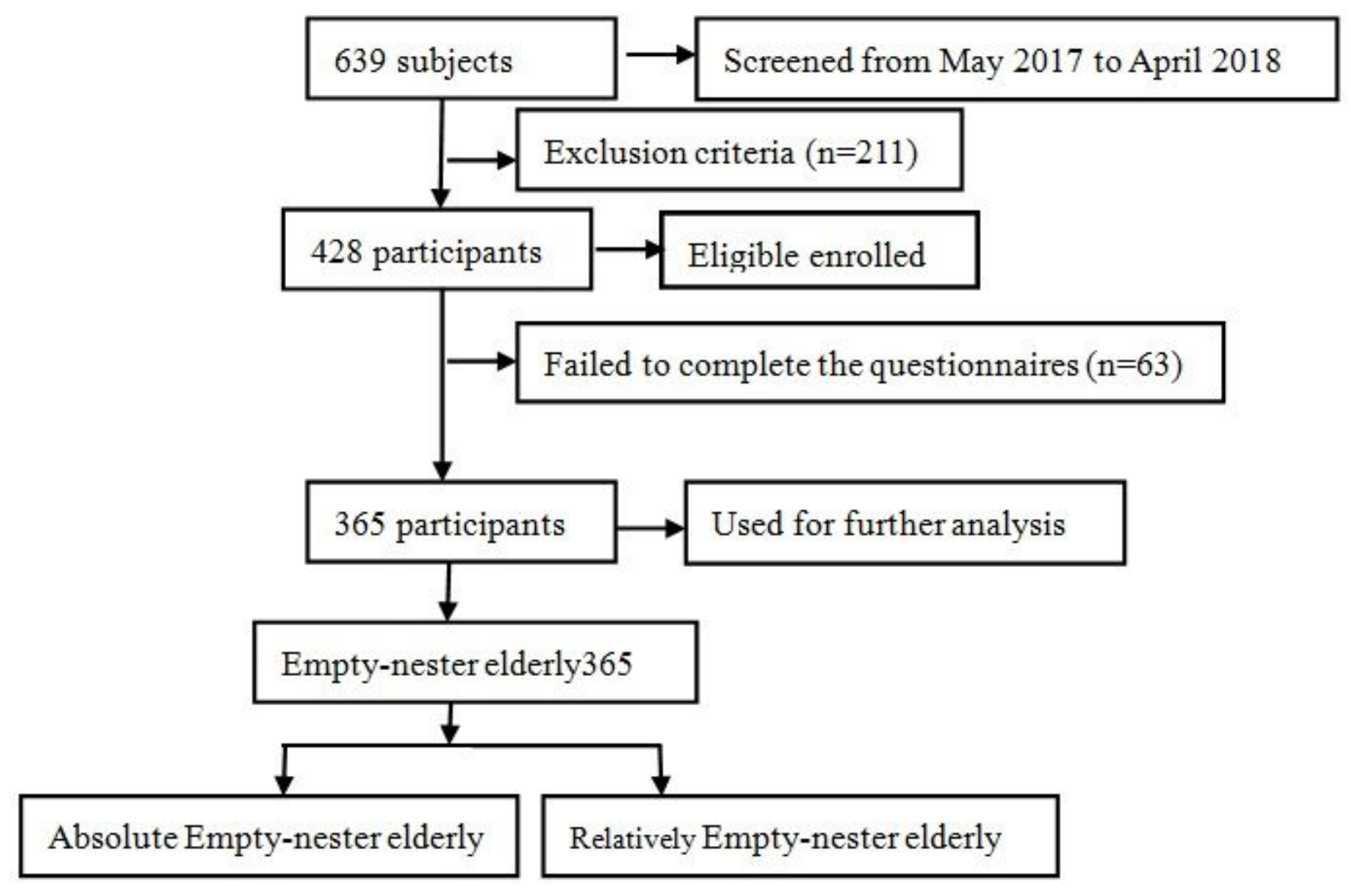

Figure 1

Flowchart of subject enrollment and screening

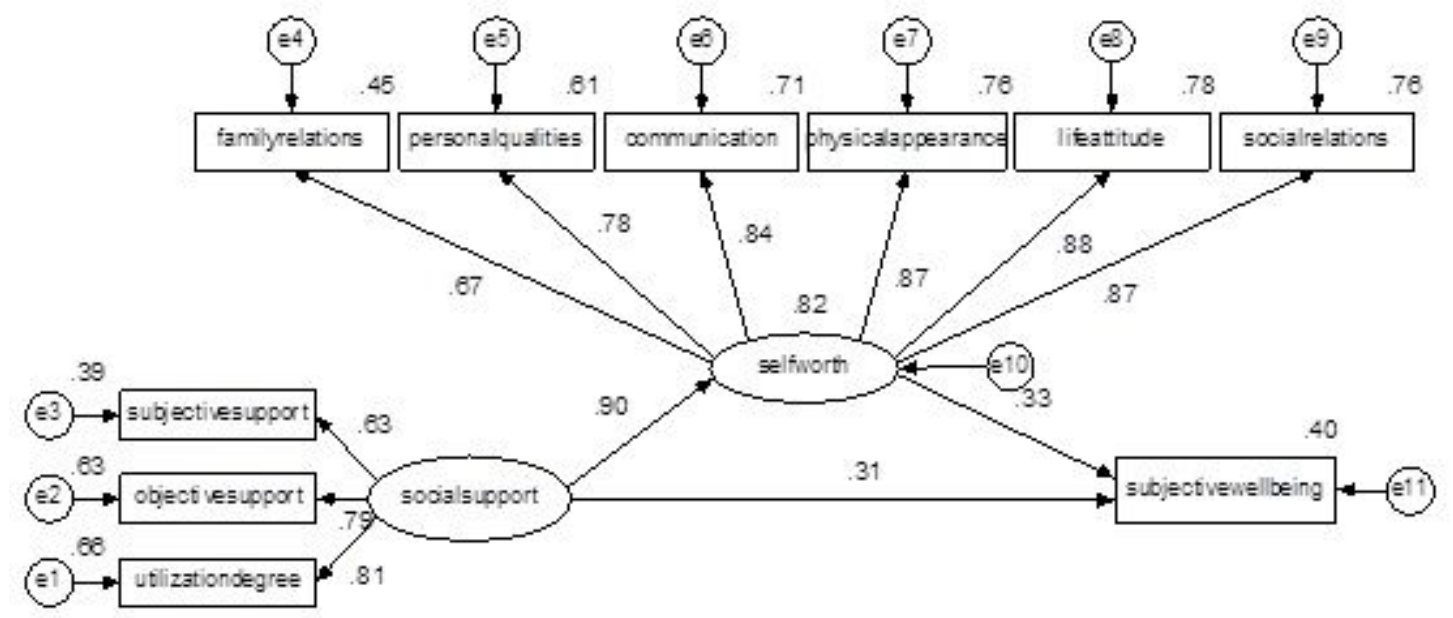

Figure 2

The structure equation model of self-worth and elf-acceptance affect Subjective well-being among rural empty-nest elderly. 


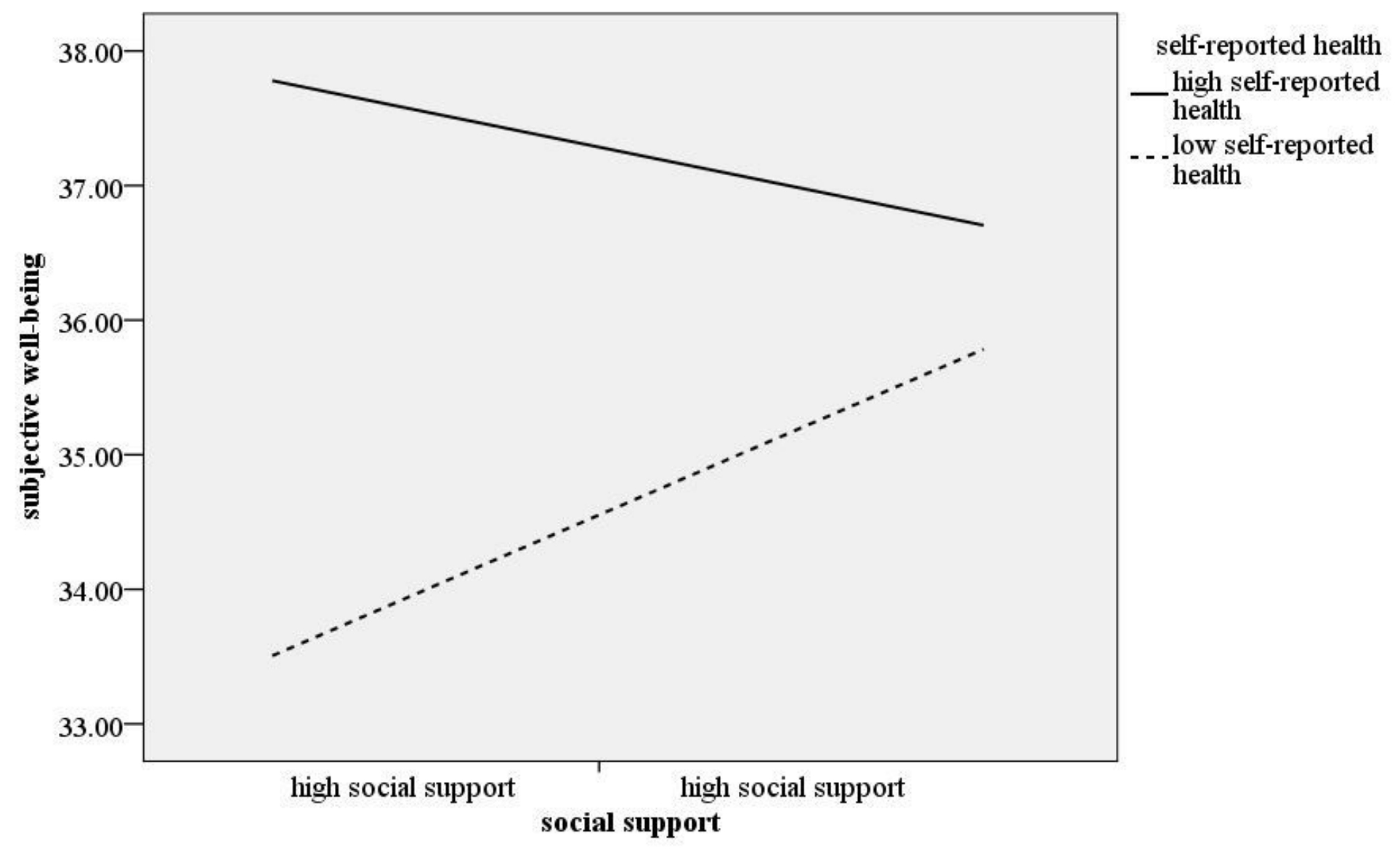

Figure 3

Results from the test of simple slopes to assess the association between social support and subjective well-being at high and low levels $(M \pm S D)$ of self-reported health. 


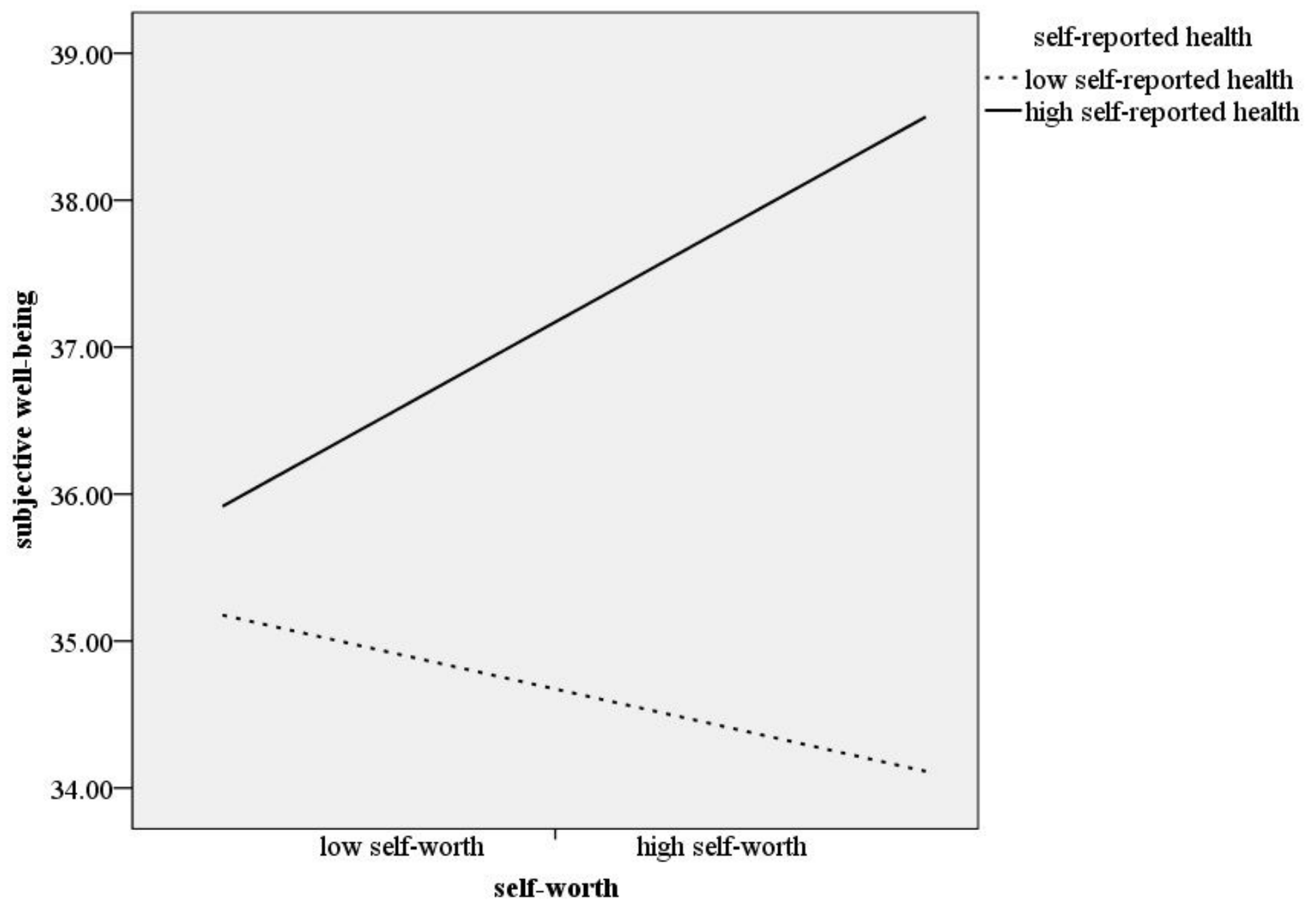

Figure 4

Results from the test of simple slopes to assess the association between self-worth and subjective wellbeing at high and low levels $(M \pm S D)$ of self-reported health. 